\title{
The Effect of Improving Mathematics Teaching in High School Art Students
}

\author{
Yingjie Liu \\ School of Mathematical Sciences \\ University of Jinan \\ Jinan City, Shandong Province, P.R. China
}

\author{
Hongkai Wang* \\ School of Mathematical Sciences \\ University of Jinan \\ Jinan City, Shandong Province, P.R. China \\ ss_wanghk@ujn.edu.cn
}

\begin{abstract}
In the process of mathematics teaching of high school art students, it is found that most high school art students has negative attitudes to mathematics learning. With the advancement of the reform of the high school mathematics curriculum, China makes efforts to carry out education that makes people satisfactory. From the perspective of teachers, this paper uses a questionnaire survey to statistically analyze the status of mathematics learning in high school arts students and applies mathematics education psychology to the current situation of the students to correctly understand the mathematics teaching of high school art students, do a good job in concept teaching, strengthen the interaction of classroom teaching, and pay attention to the exchange of emotion between teachers and students. This paper discusses how to stimulate the enthusiasm of high school art students' mathematics stud and the establishment of the self-confidence of learning mathematics, so as to urge students to study actively, improve the mathematics teaching effect of high school art students as much as possible, and provide reference for teachers in teaching.
\end{abstract}

Keywords-High school mathematics; Artistic students; Teaching strategies; Teaching effects

\section{INTRODUCTION}

With the continuous deepening of quality education, the demand for art education has increased year by year. Nowadays, most universities have set up art majors. In recent years, the proportion of art examinee in the total number of college entrance exams has increased substantially, and the "art examination" has become a topic of concern to schools, society and parents. This has made art colleges and universities increasingly demanding candidates' "threshold" for admission. Art majors are enrolling in full swing every year. So it is particularly important to improve the comprehensive ability of high school art students. The art students in senior high school generally pay more attention to the specialized courses than to the cultural courses, especially in the mathematics subject, which occupies a large proportion in the total score of the cultural class. In practical teaching, cultural teachers also have problems such as idling and letting students go free. To a certain extent, the phenomenon that art students despise cultural courses is aggravated, which violates the requirements of quality education for the all-round development of students. It is also very difficult to cultivate the necessary character and key abilities that can meet the needs of lifelong development and social development. Therefore, to change this situation is bound to lead to a "classroom revolution" [1]

\section{Definition And DeVElopment Status of ART Students}

\section{A. Definition of Art Students}

High school art students are those who study art major and take part in the general college entrance examination. The art examinee is different from the ordinary examinee. They not only need to study art major class, but also need to study culture class. However, the college entrance examination requires a relatively low score for arts candidates, and most of the colleges admitted are art colleges, including 211 engineering colleges, ordinary undergraduate colleges and specialized colleges.

\section{B. The Basic Status of Mathematics Learning of Art Students}

Because the cultural performance of art students is much lower than that of pure cultural students, and many art students learn art from an early age, they are known as "child students" who are highly qualified in their major. But the cultural background is very weak. Although it is in the high school stage, it is not clear to master the mathematics knowledge. Even for the score calculation which must be mastered in the junior middle school. The problems of solving the quadratic equation group are still unclear.

\section{Demand for High Quality Art Students in China}

Statistics from the Ministry of Education show that in recent years, the arts major has ranked first in the professional rankings where admissions growth has grown too fast. Although there are more and more schools offering art majors, many art graduates can only engage in some lower-end jobs after graduation due to the influence of faculty resources and student quality. This is inconsistent with the society's demand for artistic talent. Whether it is from the cultural and artistic industries or the requirements of the national quality education, modern society calls for and requires high-level, high-quality professional art talents. The demand for low-end talent is often saturated. Therefore, while we are striving to cultivate our exquisite artistic talents, we must also strengthen our own 
cultural and scientific literacy, and strive to be a composite talent [2] who is to be an all-round development.

Based on the above two reasons, this article explores strategies to improve mathematics teaching for high school art students.

\section{THE SIGNIFICANCE OF RESEARCH}

Due to the influx of a large number of students with low quality into art, art students are almost becoming synonymous with poor study and bad conduct.

Art in China is not mature yet, but it is also the most promising. Therefore, we should pay more attention to the improvement of students' cultural knowledge while improving the professional literacy of art students. High school art students have not yet reached their due level of mathematics learning. There is a lot of room for development; to a large extent, the reason why students can't learn mathematics well is also related to the teachers blindly using the inherent teaching methods, which restricts the development of art students in mathematics. In fact, some art students still learn mathematics very well. As long as we can explore effective methods, we will get better results. Therefore, educators should give full play to their own strength, explore effective teaching methods of mathematics, and build up their self-confidence in learning mathematics.

\section{THE STRATEGY OF High SCHOOL ART STUDENTS MATHEMATICS TEACHING}

Compared with ordinary high school students, most art students have poor academic foundation, lively and active personality, weak willpower, and easy to walk away. They mainly focus on mechanical learning. Although they have strong image thinking ability, they have poor logical thinking ability. In addition, art students need more time to improve their professional skills, and the allocation of cultural classes is necessarily less time-consuming, but high school mathematics has the characteristics of large amount of knowledge and strong abstraction. Therefore, improving mathematics teaching in a limited time is especially important. This article mainly from the perspective of mathematics teachers, combined with their own teaching experience, how to stimulate high school art students' enthusiasm and interest in mathematics learning, improve the effectiveness of classroom teaching conducted some exploration.

\section{A. To Correctly Understand The Mathematics Teaching of Art Students in Senior High School}

In addition to taking mathematics as a compulsory examination for entrance examination, the mathematics curriculum standard of senior high school also clearly points out [3]: China's ordinary senior high school education is based on compulsory education to further improve the quality of citizens and basic education for the general public. The task is to promote students' development in a comprehensive and individualized manner and prepare students for adaptation to social life, higher education, and professional development. Development lays the foundation. The training goal of ordinary high schools is to further enhance the overall quality of students, focus on developing core qualities, so that students have ideals and beliefs and social responsibility, with scientific and cultural qualities and lifelong learning capabilities, a total of independent development capabilities and communication and cooperation capabilities.

Whether it is pure culture or art students, it is necessary to learn mathematics well. However, in a sense, the classroom is the main channel for art students to learn mathematics. Therefore, it is clear that the teacher's thinking and development (toward what kind of ideal)? [4] contributing to the professional development of teachers, giving play to their leading role in classroom teaching and arousing students' enthusiasm and interest in learning mathematics is very important. The positive attitude of teachers not only infects students, but also plays a crucial role in the success or failure of teaching, Therefore, teachers should devote themselves to mathematics education and attach importance to the research and utilization of classroom behavior, which is the premise and foundation for high school art students to learn mathematics well.

\section{B. Doing Well The Preparation of Conceptual Teaching}

According to Vygoski's theory of the proximal development zone, the students' cognitive level is a process from the known region to the proximal development area to the unknown region, so for high school students, In particular, an appropriate beginning for art students is an important condition for arousing students' interest in learning. For example, in learning the concepts of function, in order to introduce the concepts of domain and range, Although students have already learned the concepts of independent variables and dependent variables in junior high school, but because the mathematics foundation of art students is generally poor, teachers are often required to clarify the concepts of independent variables and dependent variables once again in practical teaching. It is even necessary to explain it with concrete relational expressions to give students an intuitive feeling of concrete image, so as to achieve the goal of turning new knowledge into old knowledge. In addition, we must not rush to achieve success. Most mathematical concepts in senior high school are abstract and difficult to understand. If the concept teaching is carried out step by step directly, the confidence and enthusiasm of the art students in learning mathematics will be greatly reduced. Therefore, in the actual teaching process, attention should also be paid to the concretion of abstract mathematical concepts, for example, in 
the learning of mutuality, certainty and disorder, the set can be regarded as the whole class, the students in the class can be regarded as the elements in the set, and the random number of students reflects the disorder of the set. Whether or not someone belongs to the class reflects the certainty of the set. The differences among each student reflect the mutual heterogeneity of the set. The students can master abstract mathematical concepts through the analogy between the set and the class.

\section{Enhancing The Interaction of Classroom Teaching}

In view of the characteristics of high school art students, such as lively character, weak willpower, easy to wander and low interest in mathematics study, the author thinks that cultural teachers, especially mathematics teachers, in art high school should tend to be younger, more energetic and more humorous. This is conducive to narrowing the distance between teachers and students and fully arousing students' enthusiasm for learning. At the same time, teachers should also attach importance to the atmosphere of classroom teaching, because teachers' love can easily make students have a good effect on learning and improve their learning, and the emotional exchange between teachers and students. It plays a key role in the success of teaching. Thus, the boring mathematics class is transformed into a relaxing and pleasant class, which increases the students' enthusiasm for learning, but we should pay attention to grasping the scale of classroom teaching. In efforts to create a relaxing and pleasant classroom atmosphere at the same time, but also strict.

In the course of teaching, students can be organized to conduct quizzes before class, which should not be too difficult. Generally, they are the core knowledge points or typical questions of the last class, and the difficulty is best controlled within the scope that can be solved as long as you listen to lectures in class. Its purpose is to properly increase students' sense of tension, strengthen students' awareness of listening to lectures in class, and overcome students' psychological obstacles. In the teaching process, students should also be required to take good notes in class, ask questions in class properly, and have a clear affirmation of the students' answers to the correct questions. Students with incorrect or inaccurate answers should be encouraged and psychologically hinted, so that they can answer the questions themselves under the teacher's suggestion, enhance the students' sense of participation and self-confidence in the classroom, prevent their attention from being distracted, and avoid "polarization".

Because of the relatively low requirements of art students' cultural courses, the teaching process does not have to be allinclusive. If the difficulty of teaching is reasonably controlled, asylum will be taken [5]. For example, in the process of teaching the functions in Chapter II of the second edition of the second edition. Function runs through the mathematics teaching of pure culture students all the time, it is the most important part of mathematics study, but for the teaching of art students, it weakens the explanation of mapping and function application. On the one hand reduces the teaching difficulty on the other hand lightens the pressure of students' study.
In addition, in view of the easily distracted attention of art students, teachers should also pay attention to the teaching of new knowledge in the front and middle parts of the whole teaching process, and concentrate on classroom exercises in the latter half of the teaching process, as art students are mostly taught in small classes. In the course of classroom practice, teachers should "go on" and pay attention to every student, especially those with a weak foundation, because they are likely to be on the verge of "abandoning mathematics", and teachers should find out in time and conduct individual tutoring. It is also possible to enhance the sense of mutual assistance among students through mutual cooperation among the members of the group, which can help teachers share tasks and save teaching time. And the "student help students" way can not only enhance the self-confidence of the students but also stimulate the curiosity of non-students. In the process, Teachers can select students who have already done so to perform on the blackboard for the purpose of announcing answers, or to select students who have learned to explain to achieve the purpose of consolidation and encouragement, which will enhance the confidence and sense of participation of such students. Do not choose students at random, because high school students are at the junction of adolescence and adulthood, are immature and have a high self-esteem, and failure to solve problems can greatly reduce their enthusiasm for learning mathematics. At the same time, it will also increase the pressure on other students to study mathematics. Finally, we should also pay attention to the fact that it is not appropriate to do too much homework after class. On the choice of homework exercises, we should pay attention to "classics, practice, and gong" that is, classical questions, and practice and improve them. Keeping the enthusiasm of art students in learning mathematics is the primary goal. It is also necessary to note that through a large number of data, the number of female students in art students is on the high side, as the knowledge of mathematics deepens, the mathematics learning ability of girls in senior high school is declining gradually [6].

\section{Pay Attention To The Emotion Exchange Between Teachers and Students}

Teacher Liu Huashan, chairman of psychology department of East China Normal University, mentioned that "there is psychology where there are people" when talking about the significance of psychology. Teaching without emotion must be stiff. It is also because teachers and students need emotional communication, even in the era of rapid development of science and technology, high-tech can not replace the profession of teachers.

High school students are in the transition from adolescence to adulthood, and need more care. Therefore, strengthening the sense of identity between teachers and students is particularly important in teaching and educating people. However, the emotional exchange between teachers and students is not limited to classes. In life, teachers should give students more care. Establish a harmonious teacherstudent relationship. Learn more about students, care for students, affirm their strengths, win their trust and love. 


\section{ANALYSIS OF CONCLUSIONS}

\section{A. Conclusions}

Through the comparative analysis of the teaching effect of "example-rule" and "rule-example" method, this paper shows that, In the course of teaching, the "rule-example" method is more suitable for senior high school art students' mathematics study. In addition, it is found in the correlation analysis of the test scores and the midterm test scores of the art students in senior high school. There is a significant correlation between the two. The mathematics teachers who are interested in art students pay close attention to the students' state in the classroom teaching and adjust them at the right time.

\section{B. Suggestions for Teaching Art Students}

For high school art students, the initial learning may not depend on how much knowledge has been learned, as far as mathematics teaching is concerned. It is to establish a kind of enthusiasm and interest in learning mathematics between teachers and students, so that students can get a sense of satisfaction and achievement in the process of teaching. As Socrates said, what teachers teach is not a "subject" but a "method of learning".
The purpose of this paper is to arouse the attention of high school art teachers, especially mathematics teachers, and hope to provide reference for the vast number of mathematics teachers. So as to pay more attention to the "special group" of high school art students. In order to achieve the goal of giving full play to the students' main role in the classroom under the guidance of teachers, high school art students can learn professional classes well at the same time. In a word, the cultural teachers of art students have a long way to go.

\section{REFERENCES}

[1] Chen Baosheng. "Efforts to manage the education of the people satisfied" J. People's Daily. (In Chinese)

[2] Ministry of Education. "Circular of the General Office of the Ministry of Education on the completion of the work of recruiting students of some Special types of Colleges and Universities in 2017". (In Chinese)

[3] Ministry of Education of the People's Republic of China. "Ordinary High School Mathematics Curriculum Standards (2017),"People's Education Press, Beijing, pp. 2-11, December 2017. (In Chinese)

[4] Hu Qiong. "Re-understanding of the quality construction of art teachers in higher vocational education" J.cnki.mzysyj, pp.106-113. January 2010. (In Chinese)

[5] Ni Xiaohui. "Some Teaching Sentences for Art Students in Senior Three Mathematics Review" J. Time Education, vol.15, pp.65-66.2013. (In Chinese)

[6] Yu Shaowei. "Education Management of Art students in Senior High School" School Party Building and ideological Education No. 392 (21): pp.87-89. (In Chinese) 